This is an open-access article distributed under the terms of the Creative Commons Attribution License, which permits unrestricted use, distribution, and reproduction in any medium, provided the original author(s) and source are credited.

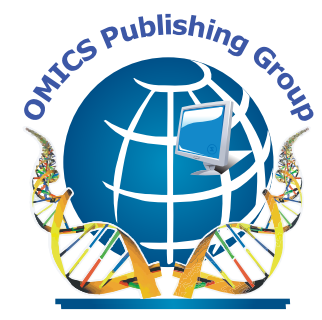

ISSN:2167-0870

\title{
Journal of Clinical Trials
}

\section{The International Open Access} Journal of Clinical Trials

\section{Executive Editors}

\section{Robert Alan Rosenheck \\ Yale University, USA}

Ulrich Rudolf Mahlknecht

Saarland University, Germany

Daniel Zelterman

Yale University, USA

Reza Hakkak

University of Arkansas for Medical Sciences, USA

Ivy M. Alexander

Yale University, USA

\section{Available online at: OMICS Publishing Group (www.omicsonline.org)}

T his article was originally published in a journal published by OMICS Publishing Group, and the attached copy is provided by OMICS Publishing Group for the author's benefit and for the benefit of the author's institution, for commercial/research/ educational use including without limitation use in instruction at your institution, sending it to specific colleagues that you know, and providing a copy to your institution's administrator.

All other uses, reproduction and distribution, including without limitation commercial reprints, selling or licensing copies or access, or posting on open internet sites, your personal or institution's website or repository, are requested to cite properly. 


\section{Rationale and Study Design of Provent-An International Multicenter Observational Study on Practice of Ventilation in Critically Ill Patients without ARDS}

Ary Serpa Neto ${ }^{1,2,3 *}$, Carmen SV Barbas ${ }^{2}$, Antonio Artigas-Raventós ${ }^{4}$, Jaume Canet ${ }^{5}$, Rogier M Determann ${ }^{1}$, Barry Dixon ${ }^{6}$, Greet Hermans $^{7}$, Samir Jaber ${ }^{8}$, Ignacio Martin-Loeches ${ }^{4}$, Christian Putensen ${ }^{9}$, Roger Smith ${ }^{6}$, Paolo Severgnini ${ }^{10}$, Markus W Hollmann ${ }^{1}$, Gary H Mills ${ }^{11}$, Marcos F Vidal Melo ${ }^{12}$, Tanja A Treschan ${ }^{13}$, Hermann Wrigge ${ }^{14}$, Jan M Binnekade ${ }^{1}$, Sabrine NT Hemmes ${ }^{1,15}$, Marcelo Gama de Abreu ${ }^{16}$, Paolo Pelosi ${ }^{17}$ and Marcus J Schultz ${ }^{1}$

${ }^{1}$ Department of Intensive Care, Academic Medical Center; Amsterdam, The Netherlands ${ }^{2}$ Department of Critical Care Medicine, Hospital Israelita Albert Einstein, São Paulo, Brazil

${ }^{3}$ Department of Critical Care Medicine, ABC Medical School, São Paulo, Brazil

${ }^{4}$ Department of Intensive Care Medicine Hospital de Sabadell, CIBER de Enfermedades Respiratorias, Corporació Sanitaria i Universitaria Parc Taulí, Sabadell, Spain

${ }^{5}$ Department of Anesthesiology, Hospital Universitari Germans Trias I Pujol, Barcelona, Spain

${ }^{6}$ Department of Intensive Care, St. Vincent Hospital, Melbourne, Australia

${ }^{7}$ Department of General Internal Medicine, Medical Intensive Care Unit, University Hospital Leuven, Leuven, Belgium

${ }^{8}$ Department of Critical Care Medicine and Anesthesiology (SAR B), Saint Eloi University Hospital, Montpellier, France

${ }^{9}$ Department of Anesthesiology and Intensive Care Medicine, University Hospital Bonn, Bonn, Germany

${ }^{10}$ Department of Environment, Health and Safety, University of Insubria, Varese, Italy

${ }^{11}$ Department of Critical Care, Sheffield Teaching Hospital; Sheffield, UK

${ }^{12}$ Department of Anesthesia, Critical Care and Pain Medicine, Harvard Medical School; Boston, MA, USA

${ }^{13}$ Department of Anaesthesiology, Düsseldorf University Hospital, Düsseldorf, Germany

${ }^{14}$ Department of Anesthesiology and Intensive Care Medicine, University of Leipzig, Leipzig, Germany

${ }^{15}$ Department of Anesthesiology, Academic Medical Center, Amsterdam, The Netherlands

${ }^{16}$ Department of Anesthesiology and Intensive Care Medicine, University Hospital Dresden, Dresden, Germany

${ }^{17}$ Department of Surgical Sciences and Integrated Diagnostics, University of Genoa, Genoa, Italy

\section{Abstract}

Background: Use of lower tidal volumes during mechanical ventilation is associated with reduced morbidity and mortality of Intensive Care Unit (ICU) patients with the Acute Respiratory Distress Syndrome (ARDS). Use of lower tidal volumes could also protect ICU patients without ARDS. While use of higher tidal volumes is strongly discouraged in ARDS patients, guidelines do not yet recommend on tidal volume size in patients not suffering from this complication, resulting in unwanted variable mechanical ventilation settings amongst ICU patients.

Purpose: The present study aims to determine ventilation characteristics, including tidal volume size in intubated and mechanically ventilated patients in ICUs in Europe, Australia and the Americas. Ventilation characteristics and outcomes are compared among patients without ARDS, patients at risk for ARDS and patients with mild, moderate or severe ARDS.

Methods: The 'PRatice of VENTilation in critically ill patients without ARDS' study (PRoVENT) is an international multicenter observational study in critically ill intubated and ventilated ICU patients by the PROVENet (PROtective VENtilation Network) investigators (http://www.provenet.eu/). At least 1,000 patients under invasive mechanical ventilation are included in a time window of 7 days, and followed up to the end of stay in ICU. The primary endpoint is the variability of tidal volume size in ventilated patients in ICUs in Europe, Australia and the Americas.

Conclusion: PRoVENT is designed to investigate and compare tidal volume settings in patients without ARDS, patients at risk for ARDS, and patients with mild, moderate or severe ARDS, and to determine the impact of tidal volume size on important clinical endpoints, in particular patients without ARDS. PRoVENT shall provide information on ventilator settings that could be used in future trials of ventilation, especially in ICU patients without or at risk for ARDS (Trial Registration: NCT01868321).

\section{Introduction}

Mechanical ventilation is a frequently applied and often life-saving strategy in critically ill patients [1]. Paradoxically, ventilation itself has the potential to worsen preexisting lung injury or even cause lung injury [2]. Ventilation-associated lung injury is suggested to result, at least in part through overstretching of aerated lung tissue and tidal recruitment of collapsed lung parts [2]. So-called 'protective ventilation' with lower tidal volumes (i.e., tidal volumes of $6 \mathrm{ml} / \mathrm{kg}$ Predicted Body Weight $(\mathrm{PBW})$ ) aiming at prevention of overstretching of lung tissue is strongly associated with reduced morbidity and mortality of Intensive Care Unit (ICU) patients with the Acute Respiratory Distress Syndrome (ARDS) [3-6], and consequently recommended in international guidelines [7].

Results from one multi-center randomized controlled trial suggest that ICU patients without ARDS could also benefit from protective ventilation with lower tidal volumes [8]. A recent meta-analysis confirmed such claim, showing an increased incidence of pulmonary complications and even increased mortality in patients who receive 'higher' or 'traditionally-sized tidal volumes' (i.e., tidal volumes of $>10$

*Corresponding author: Ary Serpa Neto, Department of Critical Care Medicine Hospital Israelita Albert Einstein, São Paulo, Brazil, E-mail: aryserpa@terra.com.br

Received October 16, 2013; Accepted October 25, 2013; Published October 28 2013

Citation: Neto AS, Barbas CSV, Raventós AA, Canet J, Determann RM, et al (2013) Rationale and Study Design of Provent-An International Multicenter Observational Study on Practice of Ventilation in Critically III Patients without ARDS. J Clin Trials 3: 146. doi:10.4172/2167-0870.1000146

Copyright: $\odot 2013$ Neto AS, et al. This is an open-access article distributed under the terms of the Creative Commons Attribution License, which permits unrestricted use, distribution, and reproduction in any medium, provided the original author and source are credited. 
Citation: Neto AS, Barbas CSV, Raventós AA, Canet J, Determann RM, et al. (2013) Rationale and Study Design of Provent-An International Multicenter Observational Study on Practice of Ventilation in Critically III Patients without ARDS. J Clin Trials 3: 146. doi:10.4172/21670870.1000146

Page 2 of 7

$\mathrm{ml} / \mathrm{kg}$ PBW) [9]. Whether we should use lower tidal volumes in ICU patients without ARDS remains debatable, since such measure can increase the need for sedation and prolonged use of muscle paralysis, possibly increasing the incidence of delirium, critical illness-associated muscle weakness, and even diaphragm dysfunction [10]. In view of the lack of evidence, guidelines inconsistently advise on tidal volume size in ICU patients without ARDS.

In view of those facts, a large well-powered randomized controlled trial comparing ventilation with lower tidal volumes with 'conventional ventilation' using traditionally-sized tidal volumes is needed to answer the question whether ICU physicians should use lower tidal volumes in all ventilated patients, including those without ARDS. Such a trial should not only use relevant clinical endpoints and pay attention to safety of use of lower tidal volumes, but also compare a lower tidal volume strategy to relevant tidal volumes in the control arm. Indeed, lower tidal volumes are increasingly used [3-6], possibly even in patients without ARDS in whom the benefits of lower tidal volumes are less certain. If studies of current practice would show that tidal volumes of $>10 \mathrm{ml} / \mathrm{kg}$ PBW by now are uncommon, a conventional ventilation arm using tidal volumes of that size may impose a significant health risk of patients in that group, and also may hamper valorization of the trial results.
The PRatice of VENTilation in critically ill patients without ARDS (PRoVENT) study aims to determine ventilation practice and outcomes of intubated and ventilated ICU patients. PRoVENT shall provide information on ventilator settings that can be used in future trials of mechanical ventilation, in particular in patients without or at risk for ARDS.

\section{Methods}

\section{Design}

The PRoVENT study is an international multicenter observational study. The Institutional Review Board of the Academic Medical Center at the University of Amsterdam, Amsterdam, The Netherlands, approved the study and analysis plan. PRoVENT is conducted in accordance with the declaration of Helsinki and is registered at www. clinicaltrials.gov (trial identification number NCT01868321). Due to the strict observational design and anonymous collection of data, informed consent is not needed in most countries-however; in certain countries individual patient informed consent is required according to local IRB regulations. Figure 1 and 2 shows the CONSORT diagram of PRoVENT.

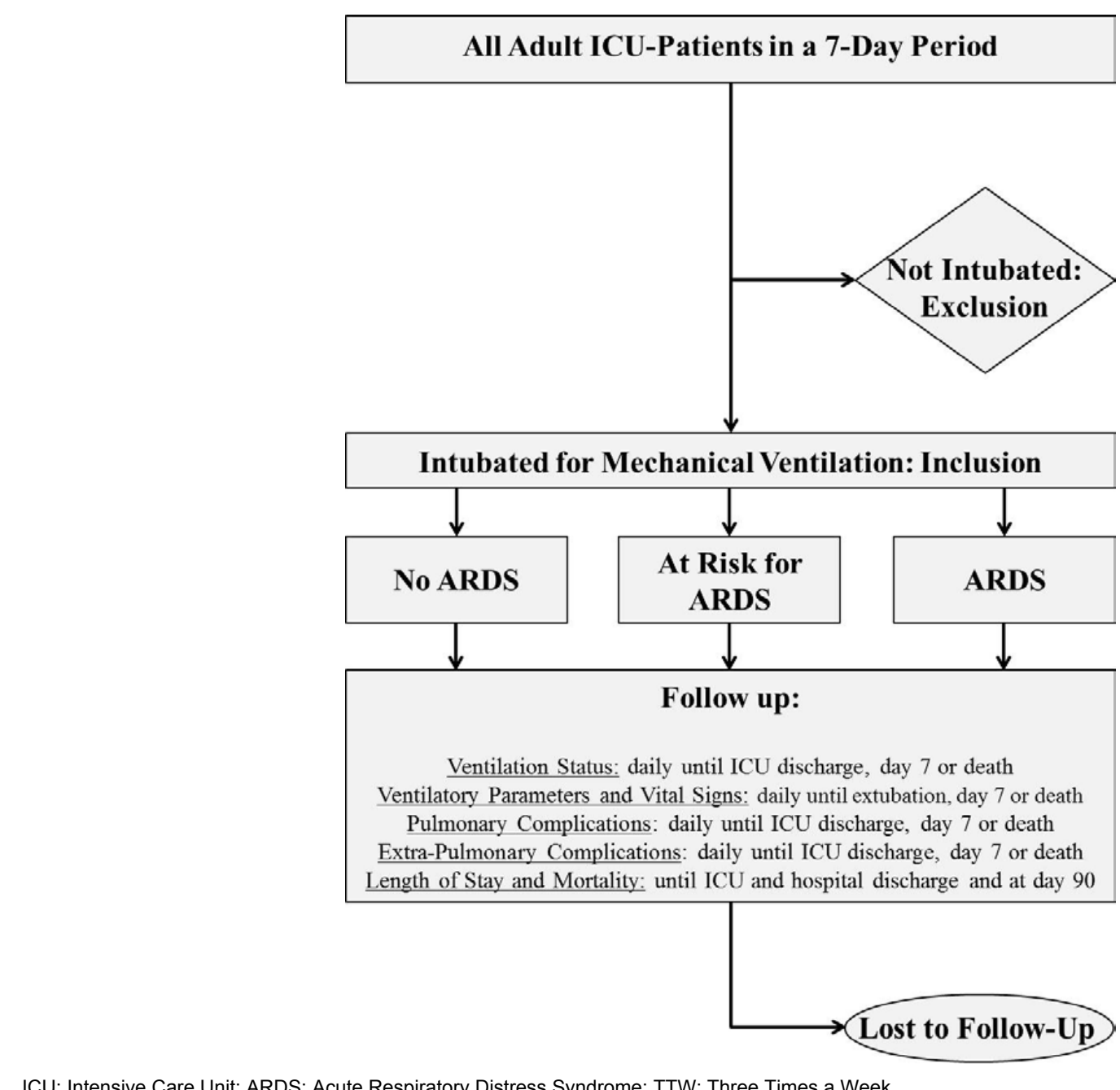

ICU: Intensive Care Unit; ARDS: Acute Respiratory Distress Syndrome; TTW: Three Times a Week

Figure 1: Flowchart of inclusion of PRoVENT. 
Citation: Neto AS, Barbas CSV, Raventós AA, Canet J, Determann RM, et al. (2013) Rationale and Study Design of Provent-An International Multicenter Observational Study on Practice of Ventilation in Critically III Patients without ARDS. J Clin Trials 3: 146. doi:10.4172/21670870.1000146

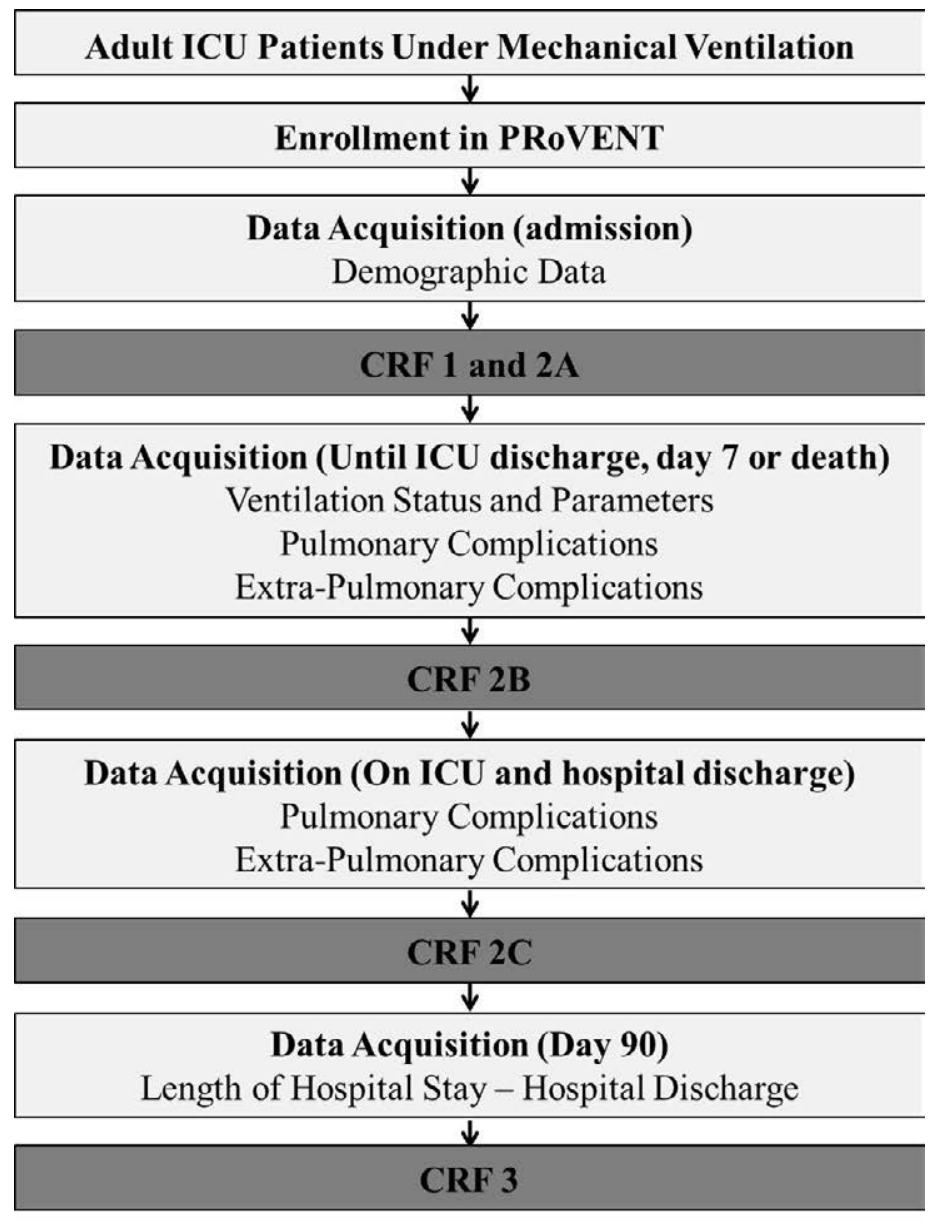

CRF: Case Report Form

Figure 2: Flowchart of follow-up of PRoVENT.

\section{Study population}

Inclusion is not restricted to patients who are intubated for mechanical ventilation in the ICU; Patients who started mechanical ventilation in the emergency room, ward, community or operating room before the present ICU admission are also eligible for participation and should be included. Age $<18$ years, use of only non-invasive ventilation not followed by invasive ventilation, patients under invasive mechanical ventilation previous to the 7-day period of inclusion, and patients transferred from another hospital under invasive mechanical ventilation represent the main exclusion criteria (Table 1).

Patients are stratified in three groups for comparison of the primary and secondary endpoints: patients without ARDS, patients without, but at risk for development of ARDS (defined as a LIPS $\geq 4$ points), and patients with ARDS. Also, patients with ARDS will be stratified according to severity of ARDS (mild, moderate and severe).

\section{Study conduct}

Local investigators will screen all patients admitted to participating ICUs during a 7-day period. This period of inclusion of patients lasts from Monday at 8:00 AM to the next Monday at 7:59 AM (in time zones of the participating centers), the starting date will be flexible for participating centers and shall be determined at a later stage together with the study coordinator.
Baseline and demographic data on all screened patients, regardless of meeting enrolment criteria are recorded (see below).

\section{Data collection}

Baseline and demographic variables are collected on the day of admission, including gender, age, height, weight, ethnicity, smoker (never, former or current), functional status (non-dependent, partially dependent, totally dependent), presence of ARDS according to Berlin definition (Table 2) [11], Lung Injury Prediction Score (LIPS) (Table 3) [12], Acute Physiology And Chronic Health Evaluation (APACHE II) score, Simplified Acute Physiology (SAPS III) score, reason for ICU admission, and reason for intubation and ventilation. In addition, it is determined whether patients have Chronic Obstructive Pulmonary Disease (COPD) with use of inhalation therapy and/or steroids, active cancer, heart failure, according to the New York Heart Association (NYHA), diabetes mellitus, chronic kidney failure with or without hemodialysis, liver cirrhosis, immunosuppression, and arterial hypertension. On the day of start of invasive ventilation the reason for mechanical ventilation is collected, as well as whether the patient received non-invasive ventilation before intubation.

Every day, until ICU discharge, death or day 7 (whichever comes first), patients are evaluated according to ventilation status (extubation or not), continuation of ventilation by non-invasive ventilation, 
Citation: Neto AS, Barbas CSV, Raventós AA, Canet J, Determann RM, et al. (2013) Rationale and Study Design of Provent-An International Multicenter Observational Study on Practice of Ventilation in Critically III Patients without ARDS. J Clin Trials 3: 146. doi:10.4172/21670870.1000146

Page 4 of 7

\begin{tabular}{|c|c|}
\hline INCLUSION CRITERIA \\
\hline 1. Admitted to a participant ICU \\
\hline 2. Intubated in the participating ICU, ER, ward, community or before the present ICU admission \\
\hline \\
\hline \\
\hline EXCLUSION CRITERIA \\
1. Age $<18$ year \\
\hline 2. Receiving only NIV \\
\hline 3. Under invasive mechanical ventilation previous to the 7-day period of inclusion \\
\hline 4. Transferred from another hospital under invasive mechanical ventilation \\
\hline ICU: Intensive Care Unit; ER: Emergency Room; OR: Operating Room; NIV: Non-Invasive Ventilation \\
\hline
\end{tabular}

Table 1: Inclusion and exclusion criteria

\begin{tabular}{|c|c|c|c|}
\hline Time & \multicolumn{3}{|c|}{ Within one week of a known clinical insult, or new/worsening respiratory symptoms } \\
\hline Chest imaging* & \multicolumn{3}{|c|}{ Bilateral opacities not fully explained by effusions, lobar/lung collapse or nodules } \\
\hline Origin of edema & \multicolumn{3}{|c|}{$\begin{array}{l}\text { Respiratory failure not fully explained by cardiac failure or fluid overload; need objective assessment to exclude hydrostatic edema if no } \\
\text { risk factor present (e.g., echocardiography) }\end{array}$} \\
\hline Oxygenation ${ }^{\star *}$ & $\begin{array}{l}\frac{\text { Mild }}{200}<\mathrm{PaO}_{2} / \mathrm{FiO}_{2}<300 \\
\text { PEEP or CPAP } \geq 5 \mathrm{~cm} \mathrm{H} \mathrm{O}^{* * *}\end{array}$ & $\begin{array}{l}\frac{\text { Moderate }}{100<\mathrm{PaO}_{2} / \mathrm{FiO}_{2}<200} \\
\mathrm{PEEP} \geq 5 \mathrm{~cm} \mathrm{H} \mathrm{H}_{2} \mathrm{O}\end{array}$ & $\begin{array}{l}\text { Severe } \\
\mathrm{PaO}_{2} / \mathrm{FiO}_{2} \leq 100 \\
\mathrm{PEEP} \geq 5 \mathrm{~cm} \mathrm{H} \mathrm{H}_{2} \mathrm{O}\end{array}$ \\
\hline \multicolumn{4}{|c|}{$\begin{array}{l}\text { ARDS: Acute Respiratory Distress Syndrome; } \mathrm{PaO}_{2}: \text { Partial Pressure Of Arterial Oxygen; } \mathrm{FiO}_{2}: \text { Inspired Fraction Of Oxygen; } \\
\text { CPAP: Continuous Positive Airway Pressure } \\
\text { *: }^{*} \text { chest X-ray or CT scan } \\
\star *: \text { if altitude higher than } 1,000 \text { meters, correction factor should be made as follows: } \mathrm{PaO}_{2} / \mathrm{FiO}_{2} 9 \text { (barometric pressure/760) } \\
\star * *: \text { this may be delivered non-invasively in the mild ARDS group }\end{array}$} \\
\hline
\end{tabular}

Table 2: The Berlin definition of ARDS [12].

\begin{tabular}{|c|c|c|c|}
\hline & LIPS points & & LIPS points \\
\hline $\begin{array}{l}\text { Predisposing Conditions } \\
\text { Shock } \\
\text { Aspiration } \\
\text { Sepsis } \\
\text { Pneumonia } \\
\text { High-risk surgery* } \\
\text { Orthopedic spine } \\
\text { Acute abdomen } \\
\text { Cardiac } \\
\text { Aortic vascular } \\
\text { High-risk trauma } \\
\text { Traumatic brain injury } \\
\text { Smoke inhalation } \\
\text { Near drowning } \\
\text { Lung contusion } \\
\text { Multiple fractures }\end{array}$ & $\begin{array}{c}2 \\
2 \\
1 \\
1.5 \\
\\
1 \\
2 \\
2.5 \\
3.5 \\
\\
2 \\
2 \\
2 \\
1.5 \\
1.5\end{array}$ & 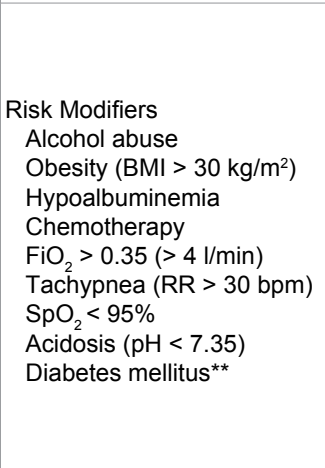 & $\begin{array}{c}1 \\
1 \\
1 \\
1 \\
2 \\
1.5 \\
1 \\
1.5 \\
-1\end{array}$ \\
\hline
\end{tabular}

Table 3: Lung Injury Prediction Score (LIPS) calculation worksheet [13]

tracheostomy, and mortality. Ventilation parameters (ventilation mode, tidal volume size, respiratory rate, peak and plateau [with volume-controlled modes] or maximum airway pressure [with pressure-controlled modes], Positive End-Expiratory Pressure (PEEP), inspired oxygen fraction, inspiration to expiration ratio, minute volume), oxygenation parameters $\left(\mathrm{PaO}_{2}, \mathrm{PaCO}_{2}\right.$, arterial bicarbonate, arterial $\mathrm{pH}$, arterial base excess, end-tidal fraction of $\mathrm{CO}_{2}$ ), vital signs (heart rate, cardiac rhythm, blood pressure, central venous pressure), transfusion requirements (red blood cell, fresh frozen plasma and platelets), daily fluid balance, sedation scores (RASS, SAS or Ramsay), and Sequential Organ Failure Assessment (SOFA) subgroups (cardiac, hepatic, respiratory, coagulation, kidney and neurologic) are recorded every day close to 08:00 AM until ICU discharge, death or day 7 (whichever comes first).

Pulmonary complications (new requirement of invasive ventilation, pulmonary infection, atelectasis, barotrauma, pleural effusion, new pulmonary infiltrates, and development or worsening of ARDS), and extrapulmonary complications (sepsis, extra-pulmonary infection, acute kidney injury and renal replacement therapy) are recorded daily until ICU discharge, death or day 7 (whichever comes first) and on ICU and hospital discharge.

On day 90, hospital-free days, ICU-free days, ventilation-free days, need of tracheostomy and mortality are recorded; if the patient is still admitted to the hospital on day 90 , this day will be recorded as last day of follow-up.

\section{Study endpoints}

The primary endpoint is the variability of size of tidal volumes used amongst diverse ICU patient categories. Secondary clinical endpoints include: 1) other ventilation parameters (including plateau pressure levels, PEEP levels, and driving pressure levels); 2) development of ARDS in patients without ARDS at the onset of mechanical ventilation; 3) worsening of ARDS in patients with ARDS at the onset of mechanical ventilation; 4) pulmonary infection; 5) other pulmonary complications (barotrauma, pleural effusion and atelectasis); 5) need for tracheostomy; 6) extra-pulmonary complications (acute kidney 
injury, renal replacement therapy, sepsis, extra-pulmonary infection); 7) number of ventilator-free days at day 28 and $90 ; 8$ ) length of stay in ICU and in hospital at day 90; 9) all-cause ICU and hospital-mortality; 10) all-cause mortality at day 90 .

All-cause mortality is defined as any death during follow-up and length of stay as the time between admission and discharge or death. Days of ventilation is defined as time between orotracheal intubation and successful extubation (in case of intermittent mechanical ventilation via a tracheostomy, every day a patient needs ventilation counts as one extra day of ventilation, irrespective of duration of ventilation that specific day) In case of non-invasive ventilation, the duration will be assessed separated from the assessment of invasive mechanical ventilation.

Pulmonary infection is defined as need of new antibiotics in the presence of new or changed lung opacities on chest X-ray and/or new or changed sputum plus at least one of the following criteria: 1) temperature $>38.3^{\circ} \mathrm{C}$; or 2) $\mathrm{WBC}$ count $>12,000$. Atelectasis is suggested by lung opacification with shift of the mediastinum, hilum, or hemidiaphragm towards the affected area, and compensatory overinflation in the adjacent nonatelectatic lung, while pleural effusion is suggest by lung opacification with shift of the mediastinum, hilum, or hemidiaphragm towards the non-affected area. Barotrauma is defined as the air in mediastinum or in the pleural space with no vascular bed surrounding the visceral pleura. ARDS is defined according to the Berlin definition and worsening of ARDS is defined as any change in the prior classification (i.e., mild to moderate or severe, or moderate to severe). Systemic Inflammatory Response Syndrome (SIRS), sepsis, severe sepsis, and septic shock is defined according to consensus criteria [13], and acute kidney injury according to the RIFLE classification system [14].

\section{Statistical Analysis Plan}

\section{Sample size calculation}

The sample size is calculated for the largest and most relevant subgroup of the primary endpoint, the tidal volume size amongst patients without ARDS and also, expresses the number of patients needed to ensure that the margin of error is small enough to remain relevant for our objective. Experience a mean \pm standard deviation tidal volume in patients without ARDS of $10 \pm 2 \mathrm{ml} / \mathrm{kg}$ PBW, considering the incidence of $30 \%$ of ARDS in the population of interest [15], with $95 \%$ confidence interval and a margin of error of 0.16 , and corrected for $10 \%$ of drop-out, the net total sample size needed is 952 patients. To correct for drop-outs (incomplete follow-up, etc), we will include at least 1,000 patients

\section{Analysis}

Normally distributed variables will be expressed by their mean and standard deviation; not normally distributed variables will be expressed by their medians and interquartile ranges; categorical variables will be expressed as $\mathrm{n}(\%)$. In test groups of continuous normally distributed variables, Student's t-test will be used. Likewise if continuous data are not normally distributed the Mann-Whitney $U$ test will be used. Categorical variables will be compared with the Chi-square test or Fisher's exact tests or when appropriate as relative risks. Statistical uncertainty will be expressed by $95 \%$ confidence levels.

Primary outcome is the tidal volume size in each group within mechanical ventilation, presented as milliliters per kilogram of predicted body weight $(\mathrm{ml} / \mathrm{kg} \mathrm{PBW})$. The $\mathrm{ml} / \mathrm{kg}$ PBW will be analyzed as continuous variables. If the data is normally distributed, one-way Analysis Of Variance (ANOVA) or two-way ANOVA assessing the time-interaction between groups and days of observation will be used. When not normally distributed the Kruskal-Wallis test or Friedman test assessing the time-interaction between groups and days of observation will be used.

Propensity score is calculated by a multivariate logistic regression model with outcome as the dependent variable, while all other covariates related to mortality is included as independent variable. Tidal volume size related to outcomes is investigated using conditional logistic regression. Also, a Cox proportional hazards model with outcomes as dependent variables and tidal volume and propensity score as covariates is used. Time-course variables (e.g., repeated measures of ventilatory parameters, vital signs, oxygenation parameters and others) are also analyzed by a linear mixed model. The linear mixed models procedure expands the Generalized Linear Model (GLM) so that the data are permitted to exhibit correlated and non-constant variability. The model includes two factors: 1) study group (fixed factor), each level of the study group factor can have a different linear effect on the value of the dependent variable; 2) time as covariate, time is considered to be a random sample from a larger population of values, the effect is not limited to the chosen times. Pre-specified subgroup analyses will be performed in the following subgroups: 1) ARDS vs. Non-ARDS; 2 ) severity of ARDS; 3 ) reason for ICU admission; 4) reason for intubation and mechanical ventilation; and 5) at risk or not for ARDS (according to LIPS).

Statistical significance is considered to be at a p-value of $<0.05$. Statistical analyses are conducted using SPSS version 20.0 (SPSS, Inc., Chicago, IL).

\section{Study Organization}

The study coordinator, the principal investigator and two additional investigators of PROVENet (http://www.provenet.eu/) form the Core Steering Committee. The Steering Committee is composed of these investigators plus the investigators involved in the design of the study and writing of the study protocol. National Coordinators are responsible for administrative management and communication with local Coordinators (in participating hospitals) and provide assistance to the participating clinical sites in study management, record keeping and data management. National Coordinators and local Coordinators are expected to guarantee the quality and security of the data collected.

\section{Discussion}

PRoVENT is an international multi-center prospective observational study that aims to determine ventilation practice and outcomes of consecutive intubated and ventilated ICU patients in a 7-day period in ICUs in Europe, Australia and the Americas. PRoVENT will help to understand current mechanical ventilation practice, in particular variability in tidal volume size, amongst patients without, at risk for or with ARDS. Results of this study can and should be used to plan future studies of mechanical ventilation in ICU patients. The sample size of PRoVENT will have power to determine the current practice of ventilation and the tidal volume size in several subgroups of mechanically ventilated patients, like those without ARDS, those at risk for ARDS and those in each severity group of ARDS.

Several observational studies in ICU patients under mechanical ventilation have been published in recent years (Table 4) [1,4,15-23]. Differences in reported tidal volume sizes between studies are large, but there is a suggestion that lower tidal volumes are increasingly used over 
Citation: Neto AS, Barbas CSV, Raventós AA, Canet J, Determann RM, et al. (2013) Rationale and Study Design of Provent-An International Multicenter Observational Study on Practice of Ventilation in Critically III Patients without ARDS. J Clin Trials 3: 146. doi:10.4172/21670870.1000146

Page 6 of 7

\begin{tabular}{|c|c|c|c|c|}
\hline First Author & Year of Publication & Study Location & Patient Selection & Tidal Volume, ml/kg PBW \\
\hline Luhr et al. [16] & 1999 & $\begin{array}{c}132 \text { ICUs in Scandinavia } \\
n=1231\end{array}$ & MV $>24$ hours & $\begin{array}{c}8.1 \text { (all patients) } \\
8.3 \text { (patients with mild ARDS)* } \\
8.3 \text { (patients with M/S ARDS) }\end{array}$ \\
\hline Valta et al. [17] & 1999 & $\begin{array}{c}1 \mathrm{ICU} \text { in Finland } \\
\quad n=59\end{array}$ & ARDS & 8.1 (all patients) \\
\hline Esteban et al. [18] & 2002 & $\begin{array}{c}361 \text { ICUs in } 20 \text { countries worldwide } \\
n=5183\end{array}$ & MV $>12$ hours & $\begin{array}{l}8.4 \text { (patients with COPD) } \\
8.6 \text { (patients with ARDS) }\end{array}$ \\
\hline Bersten et al. [19] & 2002 & $\begin{array}{c}21 \mathrm{ICUs} \text { in Australia } \\
n=168\end{array}$ & ARDS & 9.7 (patients with ARDS) \\
\hline Brun-Buisson et al. [20] & 2004 & $\begin{array}{c}78 \mathrm{ICUs} \text { in Europe } \\
n=463\end{array}$ & ARDS & 9.5 (patients with ARDS) \\
\hline Tomicic et al. [21] & 2008 & $\begin{array}{c}349 \text { ICUs in } 23 \text { countries worldwide } \\
n=4968\end{array}$ & $\mathrm{MV}>12$ hours & 9.3 (all patients) \\
\hline Linko et al. [22] & 2008 & $\begin{array}{l}19 \text { ICUs in Chile } \\
n=156\end{array}$ & MV $>12$ hours & $\begin{array}{c}9.6 \text { (all patients) } \\
9.4 \text { (patients with ARF) } \\
10.2 \text { (patients without ARDS) }\end{array}$ \\
\hline Villar et al. [23] & 2009 & $\begin{array}{c}25 \mathrm{ICUs} \text { in Finland } \\
n=958\end{array}$ & MV $>6$ hours & 8.7 (all patients) \\
\hline Esteban et al. [4] & 2011 & $\begin{array}{c}17 \text { ICUs in Spain } \\
n=255\end{array}$ & ARDS & 7.2 (all patients) \\
\hline Azevedo et al. [15] & 2013 & $\begin{array}{c}45 \text { ICUs in Brazil } \\
n=622\end{array}$ & MV $>24$ hours & $\begin{array}{l}7.3 \text { (patients without ARDS) } \\
8.1 \text { (patients with mild ARDS) } \\
7.6 \text { (patients with M/S ARDS) }\end{array}$ \\
\hline Esteban et al. [1] & 2013 & $\begin{array}{l}927 \text { ICUs in } 40 \text { countries worldwide } \\
\qquad n=8151\end{array}$ & $M V>12$ hours & 8.2 (all patients) \\
\hline
\end{tabular}

Table 4: Systematic review of literature on studies about mechanical practice ventilation and tidal volume size in critically ill patients

the last years. Previous studies lack important information, first, patient populations studied are heterogeneous, and most of the published analyses do not allow conclusions regarding ventilation practices in specific patient groups (i.e. patients without ARDS, patients at risk for ARDS, and patients with mild, moderate or severe ARDS). Furthermore, common to all previous studies, the publications do not report analyses of effects of tidal volume size on important clinical outcome measures. This information is crucial for future trials of mechanical ventilation in ICU patients. Indeed, we need to know which patients other than those with ARDS would benefit from the use of lower tidal volumes. Second, for power calculations information is needed with regard to the primary endpoint (e.g., incidence of development of ARDS, duration of mechanical ventilation, or death) of patient groups of interest in planning any trial. Third, we need to know what tidal volumes are used in groups of interest, to choose the appropriate tidal volume size in the control groups of future trials. PRoVENT is the first observational study that can provide this information.

It can be difficult and sometimes even impossible to distinguish patients without ARDS from those with mild ARDS, since previously used criteria (i.e., the American-European Consensus Criteria [24]) and present definition (i.e., the Berlin definition [11]) lack sufficient power to discriminate between patients at risk for ARDS or with mild ARDS, and between patients with mild ARDS and patients with moderate or severe ARDS [12,25]. Notably, none of the published studies so far used the new definition for ARDS [11]. Since ventilation with lower tidal volumes is well established in patients with the syndrome, failure to identify patients with mild ARDS can lead to the use of higher tidal volumes in this group of patients, potentially worsening their outcomes. The use of lower tidal volumes for all patients can potentially avoid this situation. Also, recent studies show that median tidal volume size in all subgroup of patients (without and with ARDS) was well above $6 \mathrm{ml} / \mathrm{kg}$ PBW. The reasons for lack of adherence to a lower tidal volume strategy may include concerns about adverse effects of low tidal volumes, such as hypercapnia and increased need for sedatives, insufficient knowledge of the lung protective ventilation protocols and under recognition of ARDS [15,26].

Despite the benefits associated with use of lower tidal volumes, there are some possible side effects. Use of lower tidal volumes may increases the need for sedation and even neuromuscular blockade, increasing the risk of delirium and the rate of ICU-acquired paresis [10]. Also, the use of lower levels of assistance could exhaust the respiratory muscles, leading to increased duration of mechanical ventilation [10]. Previous studies did not confirm these effects, since the use of lower tidal volume did not increase the need of sedation [27] and could be associated with a shorter hospital length of stay [9]. Well-powered, probably large, studies are needed to definitively answer these questions.

Recently, much attention has been drawn to the role of driving pressure (plateau pressure or maximal airway pressure minus PEEP) in development of ventilator-associated lung injury. Some reports suggest that higher driving pressure levels are associated with worse outcome of patients with ARDS [28-30]. With data of PRoVENT, by building a predictive model, and with the use of multivariate analyses, it could be possible to discriminate the effects of tidal volume size versus driving pressure on patient's outcomes.

In conclusion, PRoVENT is an international multicenter observational study powered to investigate the tidal volume size actually used and the outcomes of ICU-patients intubated and under mechanical ventilation without ARDS, without ARDS but at risk for and with mild, moderate or severe ARDS.

\section{References}

1. Esteban A, Frutos-Vivar F, Muriel A, Ferguson ND, Peñuelas O, et al. (2013) Evolution of mortality over time in patients receiving mechanical ventilation. Am J Respir Crit Care Med 188: 220-230. 
Citation: Neto AS, Barbas CSV, Raventós AA, Canet J, Determann RM, et al. (2013) Rationale and Study Design of Provent-An International Multicenter Observational Study on Practice of Ventilation in Critically III Patients without ARDS. J Clin Trials 3: 146. doi:10.4172/21670870.1000146

2. Slutsky AS (1999) Lung injury caused by mechanical ventilation. Chest 116 : 9S-15S.

3. Putensen C, Theuerkauf N, Zinserling J, Wrigge H, Pelosi P (2009) Metaanalysis: ventilation strategies and outcomes of the acute respiratory distress syndrome and acute lung injury. Ann Intern Med 151: 566-576.

4. Esteban A, Ferguson ND, Meade MO, Frutos-Vivar F, Apezteguia C, et al. (2008) Evolution of mechanical ventilation in response to clinical research. Am J Respir Crit Care Med 177: 170-177.

5. Matthay MA, Ware LB, Zimmerman GA (2012) The acute respiratory distress syndrome. J Clin Invest 122: 2731-2740.

6. Needham DM, Colantuoni E, Mendez-Tellez PA, Dinglas VD, Sevransky JE, et al. (2012) Lung protective mechanical ventilation and two year survival in patients with acute lung injury: prospective cohort study. BMJ 344: e2124.

7. Dellinger RP, Levy MM, Rhodes A, Annane D, Gerlach H, et al. (2013) Surviving sepsis campaign: international guidelines for management of severe sepsis and septic shock: 2012. Crit Care Med 41: 580-637.

8. Determann RM, Royakkers A, Wolthuis EK, Vlaar AP, Choi G, et al. (2010) Ventilation with lower tidal volumes as compared with conventional tida volumes for patients without acute lung injury: a preventive randomized controlled trial. Crit Care 14: R1.

9. Serpa Neto A, Cardoso SO, Manetta JA, Pereira VG, Esposito DC, et al. (2012) Association between use of lung-protective ventilation with lower tidal volumes and clinical outcomes among patients without acute respiratory distress syndrome: a meta-analysis. JAMA 308: 1651-1659.

10. Ferguson ND (2012) Low tidal volumes for all? JAMA 308: 1689-1690.

11. ARDS Definition Task Force, Ranieri VM, Rubenfeld GD, Thompson BT Ferguson ND, et al. (2012) Acute respiratory distress syndrome: the Berlin Definition. JAMA 307: 2526-2533.

12. Gajic O, Dabbagh O, Park PK, Adesanya A, Chang SY, et al. (2011) Early identification of patients at risk of acute lung injury: evaluation of lung injury prediction score in a multicenter cohort study. Am J Respir Crit Care Med 183 $462-470$

13. Bone RC (1992) Toward an epidemiology and natural history of SIRS (systemic inflammatory response syndrome) JAMA 268: 3452-3455

14. Bellomo R, Ronco C, Kellum JA, Mehta RL, Palevsky P, et al. (2004) Acute renal failure - definition, outcome measures, animal models, fluid therapy and information technology needs: the Second International Consensus Conference of the Acute Dialysis Quality Initiative (ADQI) Group. Crit Care 8: R204-R212.

15. Azevedo LC, Park M, Salluh JI, Rea-Neto A, Souza-Dantas VC, et al. (2013) Clinical outcomes of patients requiring ventilatory support in Brazilian intensive care units: a multicenter, prospective, cohort study. Crit Care 17: R63.

16. Luhr OR, Antonsen K, Karlsson M, Aardal S, Thorsteinsson A, et al. (1999) Incidence and mortality after acute respiratory failure and acute respiratory distress syndrome in Sweden, Denmark, and Iceland. The ARF Study Group. Am J Respir Crit Care Med 159: 1849-1861.
17. Valta P, Uusaro A, Nunes S, Ruokonen E, Takala J (1999) Acute respiratory distress syndrome: frequency, clinical course, and costs of care. Crit Care Med 27: $2367-2374$

18. Esteban A, Anzueto A, Frutos F, Alía I, Brochard L, et al. (2002) Characteristics and outcomes in adult patients receiving mechanical ventilation: a 28-day international study. JAMA 287: 345-355.

19. Bersten AD, Edibam C, Hunt T, Moran J; Australian and New Zealand Intensive Care Society Clinical Trials Group (2002) Incidence and mortality of acute lung injury and the acute respiratory distress syndrome in three Australian States. Am J Respir Crit Care Med 165: 443-448.

20. Brun-Buisson C, Minelli C, Bertolini G, Brazzi L, Pimentel J, et al. (2004) Epidemiology and outcome of acute lung injury in European intensive care units. Results from the ALIVE study. Intensive Care Med 30: 51-61.

21. Tomicic V, Espinoza M, Andresen M, Molina J, Calvo M, et al. (2008) [Characteristics and factors associated with mortality in patients receiving mechanical ventilation: first Chilean multicenter study]. Rev Med Chil 136: 959 967.

22. Linko R, Okkonen M, Pettilä V, Perttilä J, Parviainen I, et al. (2009) Acute respiratory failure in intensive care units. FINNALI: a prospective cohort study. Intensive Care Med 35: 1352-1361.

23. Villar J, Blanco J, Añón JM, Santos-Bouza A, Blanch L, et al. (2011) The ALIEN study: incidence and outcome of acute respiratory distress syndrome in the era of lung protective ventilation. Intensive Care Med 37: 1932-1941.

24. Bernard GR, Artigas A, Brigham KL, Carlet J, Falke K, et al. (1994) The American-European Consensus Conference on ARDS. Definitions mechanisms, relevant outcomes, and clinical trial coordination. Am J Respir Crit Care Med 149: 818-824.

25. Thille AW, Esteban A, Fernández-Segoviano $P$, Rodriguez JM, Aramburu JA et al. (2013) Comparison of the Berlin definition for acute respiratory distress syndrome with autopsy. Am J Respir Crit Care Med 187: 761-767.

26. Neto AS, Schultz MJ (2013) Lower tidal volumes in Brazil, also in patients without acute respiratory distress syndrome? Crit Care 17: 436.

27. Wolthuis EK, Veelo DP, Choi G, Determann RM, Korevaar JC, et al. (2007) Mechanical ventilation with lower tidal volumes does not influence the prescription of opioids or sedatives. Crit Care 11: R77.

28. Amato MB, Barbas CS, Medeiros DM, Magaldi RB, Schettino GP, et al. (1998) Effect of a protective-ventilation strategy on mortality in the acute respiratory distress syndrome. N Engl J Med 338: 347-354.

29. de Matos GF, Stanzani F, Passos RH, Fontana MF, Albaladejo R, et al. (2012) How large is the lung recruitability in early acute respiratory distress syndrome: a prospective case series of patients monitored by computed tomography. Crit Care 16: R4

30. Estenssoro E, Dubin A, Laffaire E, Canales H, Sáenz G, et al. (2002) Incidence, clinical course, and outcome in 217 patients with acute respiratory distress syndrome. Crit Care Med 30: 2450-2456.

Submit your next manuscript and get advantages of OMICS Group submissions

Unique features:

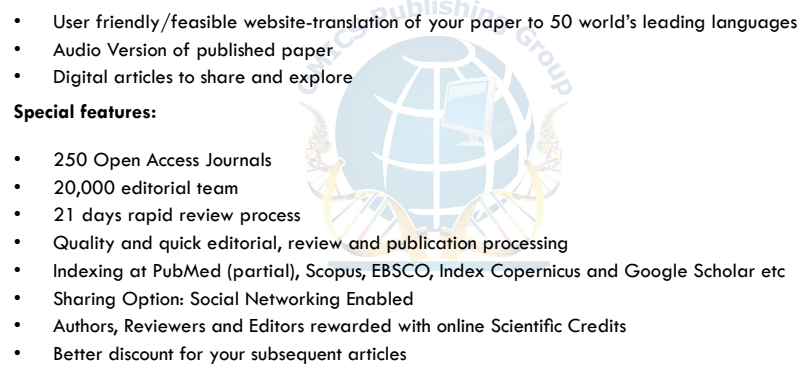

Submit your manuscript at: www.omicsonline.org/submission/
Citation: Neto AS, Barbas CSV, Raventós AA, Canet J, Determann RM, et al. (2013) Rationale and Study Design of Provent-An International Multicente Observational Study on Practice of Ventilation in Critically III Patients without ARDS. J Clin Trials 3: 146. doi:10.4172/2167-0870.1000146 